Edith Cowan University

Research Online

Research outputs 2012

$1-1-2012$

\title{
Using the critical incident technique to research decision making regarding access to training and development in medium-sized enterprises
}

\author{
Alan Coetzer \\ Janice Redmond \\ Edith Cowan University \\ Jalleh Sharafizad \\ Edith Cowan University
}

Follow this and additional works at: https://ro.ecu.edu.au/ecuworks2012

Part of the Business Commons

10.5172/ijtr.2012.10.3.164

This is an Accepted Manuscript of an article published by Taylor \& Francis in The International Journal of Training Research on 17 Dec 2014: Coetzer, A. J., Redmond, J. L., \& Sharafizad, J. (2012). Using the critical incident technique to research decision making regarding access to training and development in medium-sized enterprises. The International Journal of Training Research, 10(3), 164-178. Available here

This Journal Article is posted at Research Online.

https://ro.ecu.edu.au/ecuworks2012/503 


\title{
USING THE CRITICAL INCIDENT TECHNIQUE TO RESEARCH DECISION MAKING REGARDING ACCESS TO TRAINING AND DEVELOPMENT IN MEDIUM-SIZED ENTERPRISES
}

\begin{abstract}
Employees in small and medium-sized enterprises (SMEs) form part of a 'disadvantaged' group within the workforce that receives less access to training and development than employees in large firms. Prior research into reasons for the relatively low levels of employee participation in training and development has typically involved surveys of owner/manager opinions. A novel and potentially more fruitful line of inquiry is investigating decisions managers have actually made regarding employee access to training and development. Building on this idea, we describe how the Critical Incident Technique (CIT) was applied in our exploratory study of managerial decision making regarding employee access to training and development in medium-sized enterprises. We also discuss lessons learned in conducting the study. These lessons are based on an analysis of our experiences of using the CIT and are potentially important for researchers who will be using the technique to study similar topics in the years ahead.
\end{abstract}

Key words: Critical incident technique, decision making, training and development, employer-provided training, vocational training, medium-sized enterprises.

\section{Introduction}

Small and medium-sized enterprises (SMEs) in Australia represented 99.7\% of actively trading businesses as at June 2009 (Department of Innovation, Industry, Science and Research, 2011). These SMEs make a substantial contribution to the national economy and employment. For example, in 2009-10 SMEs contributed around 58 per cent of 
industry value added and provided employment for around $70 \%$ of total industry employment (Department of Innovation, Industry, Science and Research, 2011). Accordingly, the economic performance of the SME sector has a significant impact on national economic wealth and the quality of life of many Australians and their families. Given the economic significance of SMEs in Australia and other countries (Storey \& Greene, 2010), development of these enterprises has a crucial role in new employment creation and sustained economic growth. This includes development of the large knowledge and skills base vested in these enterprises through formal and informal learning processes (Kitching \& Blackburn, 2002).

Since the emergence of human capital theory (Becker, 1964), the idea of investing in human beings as a form of capital has fuelled interest in workplace training and development (T\&D) (see, for example, Dobbs, Sun \& Roberts, 2008; O’Keefe, Crase \& Dollery, 2007). The provision of workforce T\&D has the potential to provide benefits to both employers and employees (Becker, 1964; Storey \& Greene, 2010). Employee engagement in continuous $\mathrm{T} \& \mathrm{D}$ is widely viewed as important to the survival of organisations and as a potentially significant source of competitive advantage (Garavan, 2007; Tannebaum, 1997). Bartel's (2000) review of several US studies found that employers' annual return on investment in training varied from 7 to 50 per cent. From the perspective of employees, access to $T \& D$ is increasingly important to ensure their employability because of insecurity in employment and proliferation of flexible contracts of employment (Bulcher, Haynes \& Baxter, 2009). Furthermore, employees who make use of employer-provided and vocational training can expect their earnings to increase (Blundell, Dearden, Meghir \& Sianesi, 1999). 
However, SME employees are perceived by some commentators as a 'disadvantaged' group within the workforce (Devins, Johnson, \& Sutherland 2004) because studies in several countries have found that smaller businesses are considerably less likely to provide formal T\&D for their employees than larger businesses (Johnson, 2002; Kitching \& Blackburn, 2002; Kotey \& Folker, 2007; Smith \& Billett, 2005; Storey, 2004). This discrepancy is attributable to several factors including the greater barriers to formal T\&D faced by SMEs compared to their larger counterparts (Devins et al., 2004; Kitching \& Blackburn 2002; Kotey \& Folker 2007). These barriers include the cost of such T\&D and the opportunity cost of employees' time when they attend T\&D events. Commentators also point out that SME owners/managers are reluctant to invest in external T\&D because it usually does not focus on firm-specific problems, priorities and work practices (Gibb 1997; Johnson, 2002; Kitching \& Blackburn 2002). In Australia, where $99.7 \%$ of businesses are SMEs (Department of Innovation, Industry, Science and Research, 2011), statistical evidence on the level of employer training is mixed, with some evidence suggesting that Australia is a poor performer by international standards in the provision of training (Smith \& Billett, 2005). In contrast, Smith's (2006) analysis of statistical evidence for the extent of employer training indicates an increasing quality and quantity of training in Australian enterprises that is partly driven by government policies aimed at making nationally recognised training more available to employers and employees.

The manager's role in making human capital investment decisions is unquestionably critical. Managers often act as the primary gate keepers to $T \& D$ opportunities for employees in SMEs (Matlay, 1999; Walton, 1999). However, there is scant empirical research into factors that impinge on actual managerial decision making processes. This is surprising, given that researchers and policy makers have invested considerable energy 
over a long period of time in trying to understand how small firms can be encouraged to participate more in formal T\&D (Billett, 2004; Bishop, 2011). In this article we contend that any attempts to influence managerial decision making should be based on a thorough understanding of how decisions are actually made.

Prior research into reasons for the relatively low levels of employee participation in formal T\&D in smaller firms has typically involved surveys of owner/manager opinions regarding barriers to training, rather than an investigation of actual decisions that they have made. To illustrate, in Marlow's (1998) study a total of 28 owners or current directors were asked: 'What are major reasons why this firm has not utilised training/development initiatives?' The most common reasons were time and money. In Matlay's (1999) study, face-to-face interviews were conducted with 200 respondents in which they were asked about factors affecting actual provision of training. Three of the most important factors were cost of training, time constraints and lack of trainee cover. Kitching and Blackburn (2002) used a telephone survey to ask 1005 respondents their reasons for not wanting to provide more training for their workforces. Lost working time while workers are being trained and the financial cost of external training were the most important reasons. Mitchell (2007) conducted interviews and focus groups with small business operators, training providers, business advisors, researchers and government administrators in Western Australia (WA). Participants were asked about the reasons for the lack of uptake of training by small business personnel in WA. Major reasons were the preference of small business to learn informally on the job and the tension between the extended time needed to undertake an accredited course and the preference of small business for just-in-time training to satisfy immediate needs. These four studies illustrate 
the predominant approach to studying reasons for the relatively low levels of employee participation in T\&D in smaller firms and suggest the need for a new approach.

Building on the idea that a novel and potentially more fruitful line of inquiry is investigating decisions managers have actually made regarding employee access to $T \& D$, the objectives of the article are: (1) to illustrate the application of the Critical Incident Technique (CIT) to the research problem involving managerial decision making regarding employee access to T\&D in medium-sized enterprises; and (2) to share the lessons learned with researchers. To accomplish these objectives we have structured the rest of the paper as follows. The next section provides a brief discussion of theoretical perspectives of decision making and factors that might impinge on managerial decision making regarding T\&D. This is followed by an overview of the CIT. We then justify our decision to use the CIT and describe how the CIT was employed in our study. Next we summarise key findings of the critical incident interviews and explain how the CIT helped to cast new light on the research problem. This is followed by a discussion of the lessons that we learned that are potentially important for researchers who might contemplate using the CIT to study related topics. We make suggestions for future research before concluding the paper.

\section{Decision making regarding employee access to T\&D}

According to Albar and Jetter (2009), there are two main theoretical perspectives on decision making. Rational decision making theory focuses on the roles of logic and statistical models in decision making and is underpinned by a paradigm in which fully rational agents optimize, subject to the constraints placed on them by their environment (Berk et al., 1996; Gigerenzer \& Gaissmaier, 2011). In contrast, behavioural decision 
theory identifies several different cognitive and emotional limitations that bound human rationality (Albar \& Jetter, 2009). In behavioural decision theory, agents' capabilities are assumed to be much weaker; they may have incomplete knowledge of all available alternatives or computational abilities too limited to solve for the theoretical optimum (Berk et al., 1996).

Gigerenzer and Gaissmaier (2011) contend that the conditions for rational decision making models rarely hold in an uncertain world. Instead decision making in organizations typically involves heuristics. They define heuristics as "a strategy that ignores part of the information, with the goal of making decisions more quickly, frugally, and/or accurately than more complex methods" (p. 454). Albar and Jetter (2009) also characterize heuristic decision making as fast and frugal. In practical terms this means that because many managerial decisions are highly uncertain and involve a large number of attributes, managers tend to base their decisions on only a few attributes, such as financial criteria (Albar \& Jetter, 2009; Gigerenzer \& Gaissmaier, 2011). Furthermore, they do not always use systematic approaches to information gathering, but often rely on readily available internal information and intuition (Albar \& Jetter, 2009; Shah \& Oppenheimer, 2008). However, it is important to note that even though heuristics process less information than more complex strategies, they do have accuracies close to more complex decision models (Gigerenzer \& Gaissmaier, 2011). Therefore, decision heuristics are potentially useful for some managerial decisions (Albar \& Jetter, 2009), such as decisions regarding employee access to T\&D.

Research has identified a number of factors that impact on managerial decisions to provide employee access to T\&D. For instance, in Australia Smith and Hayton (1999) 
conducted a two-year study of the determinants of training in a range of private sector enterprises. Their study involved forty-two case studies of enterprises from five industry sectors and a national survey of 1760 enterprises. They found that the main drivers (or triggers) of training in the organizations studied were workplace change, quality improvement and the introduction of various forms of new product and process technologies. The study also identified training moderators that influenced the type of training arrangements that the enterprises eventually put in place. These moderators were: enterprise size; industry traditions of training; occupational structure; industrial relations; management attitudes; and government training policy.

Learning Network Theory (LNT) may also provide a useful framework for identifying factors that impinge on managerial decision making regarding employee access to T\&D. (For a detailed explanation of LNT see Poell et al., 2000). LNT suggests that managers' decisions regarding employee access to T\&D are shaped by both learning networks and work systems. According to LNT, different types of organizations are characterized by different types of learning networks and work systems. For example, in high-level, professional services and other knowledge-intensive services, workers typically have advanced educational qualifications and work systems in professional services organizations have traditionally involved high levels of employee discretion (Boxall \& Purcell, 2011). The learning networks in such organizations are likely to display characteristics of the external learning network. This learning network is coordinated from outside the organization by professional associations. Learning policies and programmes are inspired by new developments within the professions of the employees and learning programmes that employees attend are in fact work innovations to be introduced in the organizations by the professional field. Learning actors - those engaged 
in organizing learning - are at the heart of the learning network. In the external learning network, internal actors (employees) and external actors (professional associations) interact with each other in the development of learning policies and programs while other actors (such as managers) are less dominant in determining how the learning network operates. Thus, in some types of organizations managers are less influential in making training-related decisions than the other actors in the learning network.

\section{Overview of the CIT}

The CIT was first described by Flanagan (1954) in a classic article. In his article, Flanagan defines the CIT as "a set of procedures for collecting direct observations of human behavior in such a way as to facilitate their potential usefulness in solving practical problems and developing broad psychological principles" (p.327). As this definition suggests, initially the CIT was very behaviorally grounded and focused on differentiating effective and ineffective work behaviors in executing a task. However, over time, researchers have utilized the CIT to study a wide array of psychological constructs and experiences (Butterfield, Borgen, Amundson \& Maglio, 2004; Gremler, 2004). For example:

- Service encounter (Bitner, Booms \& Tetreault, 1990)

- Newcomer socialisation (Gundry \& Rousseau, 1994)

- Psychological contract breach (Rever-Moriyama, 1999)

- Learning facilitation (Ellinger, Watkins \& Bostrom, 1999)

- Learning processes of entrepreneurs (Cope \& Watts, 2000)

- Factors that influence decisions in incidents of work-family conflict (Powell \& Greenhaus, 2006) 
Understandably, definitions of CIT have also evolved to reflect its expanded use. For instance, according to Chell (1998), the CIT is a qualitative interview procedure which facilitates the investigation of significant occurrences (events, incidents, processes or issues) identified by the respondent, the way the occurrences are managed, and the outcomes in terms of perceived effects. The objective is to gain understanding of the incident from the perspective of the individual, taking into account cognitive, affective and behavioural elements.

The second way in which CIT has changed since it was introduced by Flanagan has to do with the relative emphasis put on direct observation versus retrospective self-report. Although Flanagan acknowledged that retrospective self-report could be used, virtually his entire article was written from the perspective of trained observers or experts collecting observations of human behavior (Butterfield et al., 2004). However, reviews of CIT studies (e.g. Butterfield et al., 2004; Gremler, 2004) suggest that a large majority of studies have used retrospective self-reports. A limitation of such studies is that they rely on the participant's ability to accurately provide a detailed account of an event (Sharoff, 2008).

One of the characteristics of the CIT is formation of categories as a result of analysing the data (Flanagan, 1954). These categories may or may not capture the context of the situation and are reductionist by definition. However, the use of CIT to study psychological constructs and experiences has been accompanied by more interpretive approaches to data analysis (Butterfield et al., 2004). Finally, over time a series of 
credibility checks have evolved aimed at enhancing the robustness of CIT findings (Butterfield et al., 2004).

\section{Justification for using CIT}

We believed that the CIT using retrospective self-reports would be an effective exploratory tool for increasing knowledge about the little-known phenomenon of managerial decision making regarding employee access to structured T\&D. We formed this view because the technique is recognised by researchers in a wide range of academic disciplines as one of the premier qualitative tools for investigating significant events (incidents) (Butterfield et al., 2004; Copes \& Watts, 2000; Gremmler, 2004; Redmann, Lambrecht \& Stitt-Gohdes, 2000; Sharoff, 2008). Another reason for using the CIT is that it focuses on respondents' accounts of significant events (incidents) that have actually happened, rather than on generalisations or opinions. As mentioned previously, prior research into reasons for the relatively low levels of employee participation in T\&D in smaller firms has typically involved surveys of owner/manager opinions, rather than an investigation of actual decisions that they have made. In the context of our study, the significant event was the manager's decision making process regarding employee access to structured T\&D opportunities that are at least partially funded by the firm. We believed that such a decision represents a difficult choice for the manager and would therefore be inherently memorable. We were also encouraged in the knowledge that the CIT using retrospective self-reports had been fruitfully employed in at least two other studies of decision making: (1) uncomfortable prescribing decisions by GPs (Bradley, 1992); and

(2) factors that influence decisions in incidents of work-family conflict (Powell \& Greenhaus, 2006). 


\section{How the CIT was employed in our study}

To address the research problem, we formulated the question: What factors are considered by managers of medium-sized enterprises when they make decisions regarding employee access to structured T\&D opportunities that are at least partially funded by the firm? The overall question guiding the study was broken into the following research objectives.

To determine the:

1. triggering factors, types of $\mathrm{T} \& \mathrm{D}$ being considered, and the perceived beneficiaries;

2. managers' decision making objectives;

3. reasons the managers made the decision they did; and

4. managers' evaluations of the effectiveness of their decisions, and reasons for their judgements.

Our research objectives were modelled on the standard format of a critical incident. A typical critical incident consists of three elements (Butterfield et al., 2004): (a) antecedent information (what led up to it) (reflected in research objective 1); (b) a detailed description of the experience itself (reflected in research objectives 2 and 3); and (c) a description of the outcome of the incident (reflected in research objective 4).

Managers who agreed to participate in our study were encouraged to prepare for the critical incident interviews by recalling and recording details of actual decisions they had made regarding employee access to structured $T \& D$ opportunities that were at least partially funded by the firm. To help them prepare in this way we sent them an incident form that they could use as a memory-aide during the interview (Bradley, 1992). The 
form provided spaces for participants to record salient aspects of the decision making process.

Interviews were conducted with a total of 14 managers of medium-sized enterprises based in Perth, Western Australia. (Table 1 provides profiles of the participants and their firms.) Given the exploratory nature of our study, no specific business sectors were targeted. This sampling approach ensured that the widest range of medium-sized firms possible could be invited to participate in the study. We focused on medium-sized firms (firms with less than 200 employees) for two reasons. First, we anticipated that employees in such firms are more likely to request access to firm-sponsored structured T\&D opportunities than employees in small firms (less than 20 employees). In fact, findings of several studies (e.g., Kitching \& Blackburn, 2002; Kotey \& Folker, 2007) show an increase in adoption of formal, structured, and development-oriented training with increasing firm size. Second, little is known about factors influencing employee access to T\&D in mediumsized firms because much of the SME literature focuses on small enterprises. As Marlow and Thompson (2008) have noted, managing staff in medium-sized enterprises presents challenges quite different from those identified in the small firm. 
Table I

Profiles of participants and their firms

\begin{tabular}{|c|c|c|c|c|c|c|c|c|c|c|c|c|c|c|}
\hline ID \# & 1 & 2 & 3 & 4 & 5 & 6 & 7 & 8 & 9 & 10 & 11 & 12 & 13 & 14 \\
\hline Gender & $\mathrm{M}$ & $\mathrm{M}$ & $\mathrm{F}$ & $\mathrm{M}$ & $\mathrm{F}$ & $\mathrm{F}$ & $\mathrm{F}$ & $\mathrm{M}$ & $\mathrm{M}$ & $\mathrm{M}$ & $\mathrm{M}$ & $\mathrm{F}$ & $\mathrm{M}$ & $\mathrm{M}$ \\
\hline Age & 55 & 51 & 45 & 27 & 34 & 41 & 25 & 55 & 44 & 34 & 59 & 43 & 50 & 53 \\
\hline $\begin{array}{l}\text { Highest } \\
\text { education }\end{array}$ & $\begin{array}{l}\text { High } \\
\text { School }\end{array}$ & TAFE & Uni & $\begin{array}{l}\text { High } \\
\text { School }\end{array}$ & Uni & Uni & Uni & Uni & $\begin{array}{l}\text { High } \\
\text { School }\end{array}$ & Uni & TAFE & $\begin{array}{l}\text { High } \\
\text { School }\end{array}$ & $\begin{array}{l}\text { High } \\
\text { School }\end{array}$ & Uni \\
\hline Position & CEO & Director & $\begin{array}{l}\mathrm{T} \& \mathrm{D} \\
\text { Manager }\end{array}$ & $\begin{array}{l}\text { Resort } \\
\text { Manager }\end{array}$ & $\begin{array}{l}\text { Co- } \\
\text { owner/ } \\
\text { Practice } \\
\text { manager }\end{array}$ & $\begin{array}{l}\text { General } \\
\text { Manager }\end{array}$ & $\begin{array}{l}\text { Assistant } \\
\text { to General } \\
\text { Manager }\end{array}$ & $\begin{array}{l}\text { General } \\
\text { Manager }\end{array}$ & $\begin{array}{l}\text { Recruitment } \\
\text { Coordinator }\end{array}$ & $\begin{array}{l}\text { Associate } \\
\text { Director }\end{array}$ & Director & $\begin{array}{l}\text { General } \\
\text { Manager }\end{array}$ & $\begin{array}{l}\text { General } \\
\text { Manager }\end{array}$ & CEO \\
\hline $\begin{array}{l}\text { Firm } \\
\text { Time } \\
(\mathrm{yrs})\end{array}$ & 10 & 15 & 6 & 1.5 & 10 & 0.2 & 0.5 & 10 & 10 & 8 & 29 & 1.3 & 11 & 0.1 \\
\hline $\begin{array}{l}\text { Business } \\
\text { type }\end{array}$ & $\begin{array}{l}\text { Mineral } \\
\text { exploration }\end{array}$ & Electrical & $\begin{array}{l}\text { Aged } \\
\text { care }\end{array}$ & Hospitality & $\begin{array}{l}\text { Legal } \\
\text { services }\end{array}$ & Hospitality & Hospitality & $\begin{array}{l}\text { Mining } \\
\text { equipment }\end{array}$ & Engineering & $\begin{array}{l}\text { Accounting } \\
\text { services }\end{array}$ & Electronics & $\begin{array}{l}\text { Chocolate } \\
\text { manufacture }\end{array}$ & $\begin{array}{l}\text { Pork } \\
\text { processing }\end{array}$ & $\begin{array}{l}\text { Fresh } \\
\text { produce } \\
\text { wholesale }\end{array}$ \\
\hline $\begin{array}{l}\text { Employee } \\
\text { Numbers }\end{array}$ & 30 & 25 & 190 & 30 & 20 & 40 & 30 & 25 & 30 & 150 & 24 & 45 & 156 & 120 \\
\hline
\end{tabular}


All procedures for the collection of data that involves human subjects were carefully adhered to and overseen by the university's human ethics committee. Prior to commencing each interview, an Information Sheet was given to the participant and its content explained. The participant then signed an Informed Consent Form. During the interview, the manager was asked to provide detailed accounts of at least three decision making incidents. For each decision making incident the manager was taken through an interview schedule designed to capture salient information about triggering factors, type of training being considered and the perceived beneficiary (research objective 1); the manager's decision making objective and reasons the manager made the decision he or she did (research objectives 2 and 3); and the manager's evaluation of the effectiveness of the decision and reasons for his or her judgement (research objective 4). To further facilitate the collection of 'rich data', probes were incorporated in the interview schedule to help the interviewer 'flesh out' the questions, and as prompts for information that the participant may have overlooked. Each interview lasted between $60-90$ minutes. With the manager's permission, the interviews were digitally recorded to ensure accuracy of the interview data. The interviews were later transcribed verbatim.

The 14 interviews yielded a total of 42 useable critical incidents that served as the units of analysis. (A summary of a critical incident account is located in Appendix I.) The interview data were sorted into six categories that were derived from the research objectives. The researchers independently analysed and placed initial interview data into the categories. The researchers then cross-checked their categorisation of the interview data and differences in categorisation of the data were reconciled. The main tactics for drawing meaning from the data were noting patterns and themes (e.g. in managers' 
decision making objectives), clustering (e.g. clusters of triggering factors) and counting (e.g. types of T\&D being considered).

\section{Key findings and fresh perspectives}

As noted previously, this paper focuses on how we applied the CIT in an exploratory study of decision making regarding employee access to T\&D in medium-sized enterprises and the lessons we learned about the CIT as a tool for investigating managerial decision making. Therefore, just a brief summary of the study's key findings are presented and discussed here. Table II presents key themes that emerged from our analysis of the critical incident accounts and for each theme we provide an example of an illustrative quotation. As the table shows, for each of the three elements of a typical critical incident we have identified two important themes associated with that element.

In regard to the first element, our findings show that employee access to T\&D was initiated primarily by managers in the organisations studied; employees did not seem to exhibit high levels of developmental proactivity. Proactive employees self-assess their future knowledge and skill needs and actively look for opportunities to expand their knowledge and skill base (van Veldhoven \& Dorenbosch, 2008). The findings also suggest that compliance with regulatory frameworks was the main training trigger. Interestingly, compliance with regulatory frameworks did not emerge as a training trigger in Smith and Hayton's (1999) study of drivers of enterprise training in Australia. From a LNT perspective, our findings in relation to the first element of a critical incident are suggestive that managers and regulatory bodies were the most influential internal and external actors respectively in organizing learning. 
Table II

Summary of Key Themes and Illustrative Quotations

\begin{tabular}{|c|c|c|}
\hline $\begin{array}{l}\text { Standard Format of } \\
\text { a Critical Incident }\end{array}$ & Theme & Example of Illustrative Quotation \\
\hline \multirow[t]{2}{*}{$\begin{array}{l}\text { What led up to the } \\
\text { incident? }\end{array}$} & $\begin{array}{l}\text { Theme 1: Managers } \\
\text { initiated employee } \\
\text { access to T\&D in most } \\
\text { critical incident } \\
\text { accounts. }\end{array}$ & $\begin{array}{l}\text { 'I have not had one [request] from an } \\
\text { employee. Every training programme } \\
\text { that I have put any of my employees } \\
\text { through had been through senior } \\
\text { management's decision.' [ID\# 2] }\end{array}$ \\
\hline & $\begin{array}{l}\text { Theme } 2 \text { : Compliance } \\
\text { with regulatory } \\
\text { frameworks was the } \\
\text { main training trigger. }\end{array}$ & $\begin{array}{l}\text { 'The only formal training we tend to do } \\
\text { is what's legislated or required by law.' } \\
\text { [ID\# 6] }\end{array}$ \\
\hline \multirow[t]{2}{*}{$\begin{array}{l}\text { The experience } \\
\text { itself - key factors } \\
\text { influencing } \\
\text { decisions. }\end{array}$} & $\begin{array}{l}\text { Theme 1: Managers } \\
\text { had a strong preference } \\
\text { for T\&D that addressed } \\
\text { immediate demands in } \\
\text { jobs. }\end{array}$ & $\begin{array}{l}\text { 'When it comes to nebulous stuff, where } \\
\text { people wish to do non-core training, I } \\
\text { would have to be in a very good mood, } \\
\text { or flush with money. It's a disruption to } \\
\text { the workplace, and there is little tangible } \\
\text { benefit to the company or even the } \\
\text { employee, because the employee would } \\
\text { soon forget.' [ID\# 1] }\end{array}$ \\
\hline & $\begin{array}{l}\text { Theme 2: Personal } \\
\text { characteristics of the } \\
\text { employee (such as } \\
\text { loyalty, commitment to } \\
\text { the organisation, and } \\
\text { work-related attitudes) } \\
\text { influenced managerial } \\
\text { decisions. }\end{array}$ & $\begin{array}{l}\text { 'We look at the abilities that they show } \\
\text {...try to select the most practical, } \\
\text { confident and loyal workers for the } \\
\text { training. Do we see them as a long term } \\
\text { potential employee who wants to grow } \\
\text { with the company? You try to pick staff } \\
\text { that you think are going to stay with the } \\
\text { company. They are the people that we } \\
\text { actually put through the training } \\
\text { courses.' [ID\# 2] }\end{array}$ \\
\hline \multirow[t]{2}{*}{$\begin{array}{l}\text { Outcomes of the } \\
\text { incident. }\end{array}$} & $\begin{array}{l}\text { Theme 1: Participants' } \\
\text { accounts of outcomes } \\
\text { of the incidents were } \\
\text { typically brief and non- } \\
\text { specific. }\end{array}$ & $\begin{array}{l}\text { 'There was the reinforcement, and the } \\
\text { new stuff that she learnt. Now she is } \\
\text { confident to just get it done, and she's } \\
\text { not stressing about it.' [ID\# 9] }\end{array}$ \\
\hline & $\begin{array}{l}\text { Theme 2: Employee } \\
\text { retention was a key } \\
\text { factor in making } \\
\text { judgments about the } \\
\text { effectiveness of } \\
\text { decisions. }\end{array}$ & $\begin{array}{l}\text { 'And he is still with us. He hasn't left, } \\
\text { so the investment was worthwhile. If he } \\
\text { left because we didn't appreciate him, } \\
\text { we would have lost an enormous amount } \\
\text { of IP walk out the door in his brain.' } \\
\text { [ID\# 11] }\end{array}$ \\
\hline
\end{tabular}


Regarding the second element, managerial preferences for $T \& D$ events that address immediate demands in jobs and the personal characteristics of the employee, such as loyalty and commitment to the organisation, were key factors influencing managerial decisions regarding employee access to $\mathrm{T} \& \mathrm{D}$. These findings are suggestive that securing a return on their investment in $T \& D$ was the primary decision making objective of the participants in our study.

In regard to the third element of a typical critical incident, the generally brief and nonspecific accounts of outcomes of the incidents are suggestive that the decision makers did not pay much attention to evaluating their decisions, nor did they give much attention to evaluating the structured $T \& D$ events. One interpretation of this finding is that the managers were not acting in accordance with good practice in both managerial decision making and T\&D. Evaluating the outcomes are important elements of both the managerial decision making process (Nelson \& Quick, 2011) and the systematic training process (Allen, 2006). Another interpretation is that the managers were using simple heuristics in their decision making and judgement. As mentioned previously, some commentators argue that heuristics are sophisticated reasoning tools based on cognitive schemas that experts hone over years of experience and that help them solve everyday problems and make fast and frugal decisions and judgements (Albar \& Jetter, 2009; Gigerenzer \& Gaissmaier, 2011). When judging the effectiveness of their decisions the managers in our study considered employee retention to be a key factor because T\&D was perceived by many participants as a mechanism for retaining key staff. In particular, managers tried to ensure workforce stability through encouraging 'stars' and 'solid citizens' (Boxall \& Purcell, 2011) to participate in low cost T\&D options, such as government-sponsored traineeships and apprenticeships. 
Some of our findings are suggestive that the CIT has the potential to provide fresh perspectives on the phenomenon of employee participation in T\&D in SMEs. To illustrate, our findings in relation to factors influencing decisions regarding employee access to structured T\&D highlighted the wide range of (often idiosyncratic) factors that the decision makers in our study considered. This is in sharp contrast to the smaller number of decision making factors that are featured in the literature that discusses 'barriers' to T\&D. Also, as mentioned previously, our findings suggest that employees in the firms studied lack developmental proactivity. However, the literature that discusses the reasons for relatively low-levels of SME engagement in formal T\&D does not mention lack of developmental proactivity on the part of employees as a potential reason. Our findings also raise doubts about the significance of some previously identified barriers to participation. For instance, lack of suitable formal T\&D opportunities for smaller firms is a frequently cited barrier to participation (Storey \& Greene, 2010; Storey \& Westhead, 1997). Yet, in our study this barrier did not emerge as an important factor in the managerial decision making process.

\section{Lessons learned}

Notwithstanding the exploratory nature of our research and the study's limitations (that we refer to in lessons 1 and 2 below), we believe that our investigation into managerial decision making regarding employee access to T\&D in medium-sized enterprises holds a number of lessons. These lessons are based on an analysis of our experiences of using the CIT and they are potentially important lessons for researchers who will be using the technique to study similar topics in the years ahead. 


\section{Lesson 1: Gathering an adequate number of critical incident accounts that are also sufficiently accurate is likely to be difficult.}

Researchers who wish to employ the CIT to investigate managerial decision making regarding employee access to $\mathrm{T} \& \mathrm{D}$ may find that gathering an adequate number of critical incident accounts is problematic. We caution researchers about this potential problem because feedback from the participants in our study suggests that decisions regarding employee access to structured T\&D opportunities that are at least partially funded by the firm are not a frequent occurrence in medium-sized enterprises. This may be because (as our findings suggest) employees in medium-sized enterprises are not proactive in seeking access to $T \& D$. In fact, managers in the organisations studied initiated employee access to T\&D in a majority (29/42) of the critical incident accounts. One possible explanation for this lack of developmental proactivity is that employees in these firms learn through socialisation processes to be reticent about requesting access to T\&D opportunities. As one manager succinctly put it: "Mostly, people know not to ask".

Additionally, the research participants are not likely to recall each element of the decision making process with the same levels of accuracy. For instance, in our study managers accurately recalled factors that triggered an employee's request to attend a training course and the factors that influenced his or her decision to approve or decline the request. However, several managers provided general or vague descriptions about outcomes of the decision as limited evaluation of decisions was conducted. As suggested by Butterfield, Borgen, Amundson and Maglio (2004), general or vague descriptions of incidents might mean an incident is not well-remembered and therefore should be excluded from the data analysis. This 'wastage' of critical incident accounts adds to problem of gathering an adequate number of critical incident accounts (as explained in the previous paragraph). 


\section{Lesson 2: Participants' accounts are subject to social desirability bias and post- decisional justification.}

The findings of studies employing the CIT to investigate managerial decision making regarding employee access to $\mathrm{T} \& \mathrm{D}$ opportunities may be prone to social desirability bias (Chung \& Monroe, 2003; Zikmund, 2003). In general, this means that some research participants may have a propensity to respond in a way that creates a favourable impression of their T\&D practices. We expect that this was indeed the case in our study. To illustrate, of the 42 critical incidents that we collected, just three incidents relate to decision making situations where employees' requests to access T\&D opportunities were declined. Furthermore, in these three critical incident accounts the decision-makers provided strong justifications for their decisions.

Findings of critical incident studies that use retrospective self-reports to investigate managerial decision making regarding employee access to $\mathrm{T} \& \mathrm{D}$ may also be prone to confirmation bias. According to Nickerson (1998, p.175) confirmation bias “...refers usually to unwitting selectivity in the acquisition and use of evidence." Confirmation bias is also known as post-decisional justification in the context of decision evaluation (McShane, Olekalns \& Travaglione, 2011). As a consequence of confirmation bias, decision makers tend to make an overly optimistic evaluation of their decisions.

The effects of confirmation bias appeared to be evident in our findings because in a large majority of the critical incident accounts the participants judged their decisions to be effective. The participants tended to judge the effectiveness of their decisions by looking to the effectiveness of the training itself. Training effectiveness was assessed by the 
participants in a largely subjective manner; they relied primarily on the workplace supervisor's observations of employee performance back at the workplace and employees' reactions to the training (Did they like it? Did they think it was useful?). Consequently, few were able to offer information which indicated that the T\&D event had closed the performance gap that triggered the T\&D decision.

\section{Lesson 3: The CIT is an effective tool for increasing knowledge about managerial decision making regarding employee access to $T \& D$.}

Managerial decision making regarding employee access to $T \& D$ is undoubtedly difficult to study. For instance, there are a multiplicity of factors that might influence the manager's decisions, such as the cost of the requested training, timing of the training, characteristics of the employee requesting access to training, and the perceived beneficiaries of the training. An additional factor that complicates the study of managerial decision making is that decision making is influenced by both rational and emotional processes (Naqvi, Shiv \& Bechara, 2006). Furthermore, Cohen, March and Olsen (1972) have drawn attention to the messiness of actual decision making processes in organizations.

As noted previously, primarily closed-ended research methods with limited scope have been applied to the research problem. Such methods are likely to provide limited insight into the complex phenomenon of managerial decision making regarding employee access to T\&D. On the other hand, open-ended approaches to studying the phenomenon are likely to be difficult to administer. The CIT is a method that balances the freedom of the respondent to react to what he or she feels is important as provided by opened-ended research methods and the speed and ease of administration provided by closed-ended 
methods (Swan \& Rao, 1975). In other words, the CIT allows study participants as free a range of responses as possible within the overall guiding research framework (Gremler, 2004). Thus, the CIT provides both flexibility and focus. These two qualities of the CIT make it ideally suited to studying the complex phenomenon of managerial decision making regarding employee access to T\&D. Additionally, the incident form that we provided to participants helped to further focus and bound the data collection, without overly constraining participant responses. As noted previously, some managers in our study used the incident form as a tool to prepare for the interview and as a memory-aide during the interview.

\section{Lesson 4: The CIT generates data that provides a holistic and potentially realistic view of managerial decision making}

In our opinion, a strength of the CIT as a tool for studying managerial decisions regarding employee access to $\mathrm{T} \& \mathrm{D}$ is that it generates data which gives the researcher a holistic view of decision making situations. This includes data about factors leading up to the decision making situation, data about the actual decision that was made, and data about outcomes of the decision. As mentioned previously, a typical critical incident consists of three similar elements (Butterfield et al., 2004): (a) antecedent information (what led up to it); (b) a detailed description of the experience itself; and (c) a description of the outcome of the incident. This close correspondence between the broad elements of a decision making situation and the elements of a typical critical incident is suggestive that the CIT is ideally suited to the study of managerial decision making situations. In addition to the strength associated with holism, a further strength of the CIT is the potential realism of the approach. The CIT enables the researcher to capture the complexity and 
idiosyncrasies of the managerial decision making process. This would not be possible using closed-ended approaches such as mail questionnaires or internet surveys.

\section{Future research}

Although there are several potential avenues for future research, just four are mentioned here. First, the CIT provides a potentially fruitful method for confirming findings of previous research into barriers to employee participation in $T \& D$ events and for casting new light on barriers to participation. Such research should involve analysis of incidents when employees requested access to $\mathrm{T} \& \mathrm{D}$ events and their managers denied access as well as incidents when managers were uncertain about whether to grant or deny access. Second, the CIT could also help to reveal design features of formal T\&D programmes that appeal to managers in SMEs. To reveal these design features researchers should analyse incidents when employees requested access to T\&D events and their managers almost immediately granted access. Third, researchers who prefer not to confine their work to the SME context could employ the CIT to investigate managerial decision making regarding employee access to T\&D events in relation to other 'disadvantaged' groups in the workforce, such as older workers (National Centre for Vocational Education Research, 2011). Fourth, the CIT could be fruitfully employed to capture employees' perspectives of factors that affect managers' decisions when employees request access to T\&D opportunities. Findings of such a study could also help to (dis)confirm the finding of our study that employees in smaller firms seem to lack developmental proactivity. Obviously, much work remains to be done. 


\section{Conclusion}

Prior research into reasons for the relatively low levels of employee participation in T\&D in SMEs has focussed on opinions of owners/managers regarding barriers to participation, rather than actual decisions that they have made. In this paper we contend that any attempts to influence owner/manager decision making by those who are trying to build capability for SME growth or promote the concept of life-long learning and associated policy initiatives to the workforce in the SME sector should be based on a thorough understanding of how decisions are actually made. We also posit that the CIT is an effective exploratory tool for increasing knowledge about the little-known phenomenon of owner/manager decision making regarding employee access to T\&D.

This article describes how CIT was applied in our exploratory study of managerial decision making regarding employee access to T\&D in medium-sized enterprises and discusses lessons we learned about the CIT in conducting the study. Analysis of our experiences suggests that the CIT has several strengths. To name but three, it allows participants as free a range of responses as possible within the overall research framework and provides both a realistic and holistic approach to studying managerial decision making. On the other hand, it is highly reliant on participants' abilities to accurately recall decisions and it is subject to social desirability bias and confirmation bias. Overall, our findings suggest that the novel approach of using the CIT to study decisions managers have actually made is a fruitful line of inquiry and has potential to provide fresh perspectives on the unresolved problem of low levels of SME participation in T\&D. 


\section{Appendix I}

\section{Summary of a Critical Incident Account}

John (ID\#8) is 55 years old and has a university education. He is the General Manager of a mining equipment firm which has 25 employees. John has been in the firm for 10 years now and like all managers is used to making lots of decisions on a daily basis. John's training decisions generally involved management identifying trade staff needing tickets to comply with regulations. However, one of his salient training decisions had come from the employees themselves. Some of the older trade assistants approached management to ask if management would support them completing fast track apprenticeships.

John immediately recognised that this offered a potential win-win opportunity. It would be a good strategic decision for management as the mining boom in Western Australia was causing significant skill shortages and the company was struggling to find enough qualified staff to enable them to compete for major contracts. It would also provide management with the opportunity to reward and help those staff that had been loyal to the company to gain trade qualifications in minimal time. John realized that there was a risk that they could lose the staff post qualification but it would ensure that he had them available for the next 18 months and that was about as good a guarantee as he could get in the current climate, perhaps better. John agreed to put them through the fast track apprenticeships after looking at each individual's capabilities and commitment to the organisation and the time that they've been working as a trade assistant. As John explained, "We're enhancing their skills to give benefits to the business so that they can do other functions in the business and we've then got skilled people in the long term, not just our company, but for other places in Australia."

For John and the company the outcome has been very effective. The company now has several more trade qualified staff and appreciative staff as they knew they had the skill but they had never been given the opportunity to go and do the qualification when they were younger. John could also see the broader benefits of his decision. "Basically its effective for the good of Australia - it will give them more skilled people - it was a new chance for our staff, and also it was better for us because like I said earlier, it helps us to handle our workload. Just like we envisaged it's been a win-win solution." 


\section{REFERENCES}

Albar, F. M., \& Jetter, A. J. (2009). Heuristics in decision making, in PICMET 2009 Proceedings, August 2-6, Portland, Oregon USA, pp. 578-584.

Allen, C. (2006). Overview and evolution of the ADDIE training system. Advances in Developing Human Resources, 8(4), 430-441.

Bartel, A.P. (2000). Measuring the employer's return on investments in training: Evidence from the literature. Industrial Relations, 39(3), 502-524.

Becker, G. (1964). Human capital: A theoretical analysis with special reference to education. Columbia University Press, New York.

Billett, S. (2004). Workplace participatory practices: Conceptualising workplaces as learning environments. Journal of Workplace Learning, 16(6), 312-324.

Bishop, D. (2011). The importance of being an insider: How networks influence the small firm's engagement with formal training. Journal of European Industrial Training, 35(4), 326344.

Bitner, M.J., Booms, B.H., \& Tetreault, M.S. (1990). The service encounter: Diagnosing favourable and unfavourable incidents. Journal of Marketing, 54, 71-84.

Blundell, R., Dearden, L., Meghir, C., \& Sianesi, B. (1999). Human capital investment: The returns from education and training to the individual, the firm and the economy. Fiscal Studies, 20, 1-23.

Boxall, P., \& Purcell, J. (2011). Strategy and human resource management. ( $3^{\text {rd }}$ ed.) Palgrave MacMillan, United Kingdom.

Bradley, C.P. (1992). Factors which influence the decision whether or not to prescribe: the dilemma facing general practitioners. British Journal of General Practice, 42, 454-458.

Bulcher, S., Haynes, M., \& Baxter, J. (2009). Casual employment in Australia: The influence of employment contract on financial well-being. Journal of Sociology, 45(3), 271-289.

Butterfield, L., Borgen, W.A., Amundson, N.E., \& Maglio, A.T. (2004). Fifty years of the critical incident technique: 1954-2004 and beyond. Qualitative Research, 5(4), 475-497.

Chell, E. (1998). Critical Incident Technique, in Qualitative Methods and Analysis in Organizational Research: A Practical Guide, eds G. Symon \& C. Cassell, Sage, London.

Chung, J., \& Monroe, S. G. (2003). Exploring social desirability bias. Journal of Business Ethics, 44, 291-302.

Cohen, M. D., March, J. G., \& Olsen, J. P. (1972). A garbage can model of organisational choice. Administrative Science Quarterly, 17(1), 1-25. 
Cope, J., \& Watts, G. (2000). Learning by doing: An exploration of experience, critical incidents and reflection in entrepreneurial learning. International Journal of Entrepreneurial Behaviour \& Research, 6(3), 104-124.

Department of Innovation Industry, Science and Research. (2011). Key statistics - Australian small business.

http://www.innovation.gov.au/SmallBusiness/KeyFacts/Documents/SmallBusinessPublicatio n.pdf (accessed 12 January 2012).

Devins, D., Johnson, S., \& Sutherland, J. (2004). Employer characteristics and employee training outcomes in UK SMEs: A multivariate analysis. Journal of Small Business and Enterprise Development, 11(4), 449-457.

Dobbs, R.L., Sun, J.Y., \& Roberts, P.B. (2008). Human capital and screening theories: Implications for human resource development. Advances in Developing Human Resources, 10(6), 788-801.

Ellinger, A. D, Watkins, K. E., \& Bostrom, R. (1999). Managers as facilitators of learning in Learning Organizations. Human Resource Development Quarterly, 10(2), 105-125.

Flanagan, J.C. (1954). The critical incident technique. Psychological Bulletin, 1, 327-358.

Garavan, T.N. (2007). A strategic perspective on human resource development. Advances in Developing Human Resources, 9(1), 11-30.

Gibb, A.A. (1997). Small firms' training and competitiveness. Building upon small business as a learning organisation. International Small Business Journal, 15(3), 13-29.

Gigerenzer, G., \& Gaissmaier, W. (2011). Heuristic decision making. The Annual Review of Psychology, 62, 451-482.

Gremler, D.D. (2004). The critical incident technique in service research. Journal of Service Research, 7(1), 65-89.

Gundry, L.K., Rousseau, D.M. (1994). Critical incidents in communicating culture to newcomers: The meaning is the message. Human Relations, 47(9), 1063-1088.

Johnson, S. (2002). Lifelong learning and SMEs: Issues for research and policy. Journal of Small Business and Enterprise Development, 9(3), 285-295.

Kitching, J., \& Blackburn, R.A. (2002). The nature of training and motivation to train in small firms. Small Business Research Centre, Kingston University, London.

Kotey, B., \& Folker, C. (2007). Employee training in SMEs: Effect of size and firm type family and nonfamily. Journal of Small Business Management, 45(2), 214-238.

Marlow, S., \& Thompson, A. (2008). Growing pains: managing the employment relationship in medium-sized enterprises in International Handbook of Entrepreneurship and HR., eds R. Barrett \& S. Mayson, Edward Elgar, Cheltenham UK. 
Marlow, S. (1998). So much opportunity - so little take up: the use of training in smaller firms. Journal of Small Business and Enterprise Development, 5(1), 38 - 48.

Matlay, H. (1999). Employee relations in small firms: A micro-business perspective. Employee Relations, 21(3), 285-295.

McShane, S., Olekalns, M., \& Travaglione, T. (2010). Organisational behaviour on the Pacific Rim. 3rd. Ed, North Ryde, NSW: McGraw-Hill.

Mitchell, J. (2007). Overcoming "I'm too busy" - An audit of small business training in Western Australia. Department of Education and Training, Western Australia. http://www.stb.wa.gov.au/SiteCollectionDocuments/report_overcoming_im_too_busy.pdf (accessed 12 January 2012).

National Centre for Vocational Educational Research. (2011). Older workers research readings. Department of Education, Employment and Workplace Relations, Australia.

Naqvi, N., Shiv, B., \& Bechara, A. (2006). The role of emotion in decision making: A cognitive neuroscience perspective. Current Directions in Psychological Science, 15(5), 260264.

Nelson, D.L. \& Quick, J.C. (2011). Organizational behaviour: Science, the real world, and you. ( $7^{\text {th }}$ ed.), South-Western Cengage Learning, Mason, Ohio.

Nickerson, S. R. (1998). Confirmation bias: A ubiquitous phenomenon in many guises. Review of General Psychology, 2(2), 175-230.

O'Keefe, S., Crase, L., \& Dollery, B. (2007). 'Does the reality of workplace training match the theory? An analysis of public sector employees' training decisions', International Journal of Training Research, vol 5, no. 2, pp41-54.

Powell, G.N., \& Greenhaus, J.H. (2006). Managing incidents of work-family conflict: A decision making perspective. Human Relations, 59(9), 1179-1212.

Redmann, D. H., Lambrecht, J. J., \& Stitt-Gohdes, W. L. (2000). The critical incident technique: A tool for qualitative research. The Delta Pi Epsilon Journal, 42(3), 132-153.

Rever-Moriyama, S.D. (1999). Do unto others: The role of psychological contract breach, violation, justice, and trust on retaliation behaviours. Unpublished doctoral dissertation, University of Calgary, Calgary, Alberta, Canada.

Shah, A. K., \& Oppenheimer, D. M. (2008). Heuristics made easy: An effort-reduction framework. American Psychological Association, 134(2), 207-222.

Sharoff, L. (2008). Critique of the critical incident technique. Journal of Research in Nursing, 13(4), 301-309.

Smith, A. (2006). The development of employer training in Australia. Education + Training, 48(4), 252-261. 
Smith, A., \& Billett, S., (2005). Myth and reality: Employer sponsored training in Australia. International Journal of Training Research, 3(2), 16-29.

Smith, A., \& Hayton, G. (1999). What drives enterprise training? Evidence from Australia. The International Journal of Human Resource Management, 10(2), 251-272.

Storey, D.J. (2004). Exploring the link, among small firms, between management training and firm performance: a comparison between the UK and other OECD countries. International Journal of Human Resource Management, 15(1), 112-130.

Storey, D.J., \& Greene, F.J. (2010). Small business and entrepreneurship. Prentice Hall, Harlow, England.

Storey, D.J., \& Westhead, P. (1997). Management training in small firms: A case of market failure?. Human Resource Management Journal, 7(2), 61-71.

Swan, E. J., \& Rao, C. P. (1975). The critical incident technique: A flexible method for the identification of salient product attributes. Journal of the Academy of Marketing Science, 3(3), 296-308.

Tannebaum, S. I. (1997). Enhancing continuous learning: Diagnostic findings from multiple companies. Human Resource Management, 36(4), 437-452.

Van Veldhoven, M., \& Dorenbosch, L. (2008). Age, proactivity and career development. Career Development International, 13(2), 112-131.

Walton, J. (1999). Strategic human resource development. Prentice Hall, Harlow, England.

Zikmund, W.G. (2003) Business research methods. (7th ed.), The Dryden Press, Orlando, FL. 